\title{
Bullying Phenomenon: Perceptions of Elementary School Students
}

\author{
Dr. Ledia Kashahu (Xhelilaj) \\ University "Aleksander Moisiu" Durrës, Albania \\ Faculty of Education, Department of Pedagogy \\ E mail: kashahuledia@yahoo.com \\ Dr. Jozef Bushati \\ University of Shkodra "Luigj Gurakuqi", Albania \\ Advising Information Student Center \\ E mail: jozefbushati@gmail.com
}

\section{MA. Haxhire Osmani}

\section{Doi:10.5901/jesr.2014.v4n4p0480}

\begin{abstract}
This study is quantitative by his nature and aims to deep knowledge about the phenomenon in the context of Albania's bullying, based on the reports of 230 students from low cycle of 9-year school of Durres District. The purpose of this study is to explore students' perceptions of themselves in some aspects as: a) why some students fall victim's bullying; b) in which the school environment with many behaviors occur bullying; c) what are the attitudes of the spectators of this phenomenon and d) whether there is a gender difference for victims' bullying. To achieve these goals the study were randomly selected 6 schools in the Durres District, and in them are randomly selected but were stratified 121 girls and 109 boys of grades 5-6, who reported via an adjusted instrument from their literature perceptions. The collected data were processed with SPSS, which were carried out mainly descriptive analysis, and coretional analysis. The study revealed that there are many reasons why students fall victim of bullying behavior, but are foremost due to the origin of the families, the ways in which students dress, lack of athletic skills, and being overweight. Bullying acts occur more often when there are not teachers in the classroom, in school hallways and during entrances - exits in school. Nearly 1 in 3 students tend to report to adults that if they are present when these behavior occur, whether 1 in 4 students results that see, what happen without becoming part with bully, and 1 in 5 students try to stop's bullying. In addition, it was found that there are not gender differences in terms of victimization and aggression. The authors also discussed several ways in accordance with Albanian contexts ban is bullying in schools.
\end{abstract}

Keywords: bullying, bully, victim, family origins, bystanders,

\section{Introduction}

Numerous studies conducted worldwide have identified that children tend to show aggressive behavior toward each other (Nelson, Hart, Yang, Olsen, and Jin, 2006; Perren and Alsaker, 2006; Ortega and Monks, 2005; Ostrov, 2008; Russell et al., 2003 Shahim, 2008; Shin and Kim, 2008). Aggression in childhood is regarded as a social problem, which carries consequences for both the victim and the aggressor (Guerra \& Leidy, 2008). There is a consensus in Western research tradition in determining's bullying as repeated aggressive behavior against someone who has not be easy to defend himself (Olweus, 1999; Ross, 2002). Researchers define bulling as a special type of aggression, which is characterized by asymmetry of power-force between bull and victim and repeatedly the behavior consistently (Olweus, 1999; Solberg \& Olweus, 2003). Rigby (2002) gave a similar definition, which determines bullying as "systematic abuse of power". According to Nansel and his colleagues (2001), bullying behaviors have tendency to grow during adolescence, peaks in early adulthood and begin to fall gradually in the last years of adolescence.

Bullying is a behavior that plagues school as well as family because already widely known negative consequences of the involvement in bullying behavior as for bull as well as for the victim (Lemstra, Nielsen, Rogers, Thompson, and Moraros, 2012). Bullying behavior causes victimization based on individual basis discrimination and yet, it is associated with specific characteristics among peer groups. Nowadays there is a growing around public opinion on the international level in terms of increased aggression in schools, having as reference the issue of human rights. According to Greene (2006), this increased sensibility related aggressive behaviors, has made consciously for legislation in force in all

$$
\sim 480 \sim
$$


countries, to have measures to prevent and isolate all forms of discrimination, such as discrimination with race nature, gender, religion, disability or sexual orientation. On the other hand, since in 1993 Olweus stated that the protection of children's from bullying is a "fundamental democratic right."

Pupils in school perform bullying behavior for many reasons. According to Thornberg, (2010), two of the main reasons why students are performing bullying behavior; a) To enhance the status and b) To increase the impact and the strength of their peers. 's Bullying is used to enhance the status of the bull in-group, at the expense of the victim, who is excluded from the group (Jones, Haslam, York, and Ryan, 2008). Bullying often influences to create division in groups. A bully who defines what is different in the pupil community creates the group of 'us' and 'them' and through the definition gains acceptance for the values represented by 'us'. This definition creates a status within the community and the means of bullying create fear of the social punishment to follow (Hamarus and Kaikkonen, 2008, p. 342). Besag, (2006) argues that's verbal bullying or other forms of it place among the girls because of their efforts to gain the friendship of peers but also popularity.

While Burns and his colleagues (2008) found that not only to enhance their status and gain popularity, but also for pleasure. Lam and Liu in 2007 carried out a study to discover the factors that encourages bullying. They found that perceptions of bull victims add bullying because they deserve it for the reason that they not know to follow group norms. Group support was also an encouraging factor, creating a diffusion of responsibility and a feeling of just following the group norms. In addition, acting as bully gave 'them a sense of strength, status and potency not attainable from schoolwork or from home' (Lam and Liu, 2007 p. 67).

In a recent study conducted in Canada was found that bullying behaviors have higher intensity in schools with low supervision of adults. Specifically, elementary school students are at risk on school grounds, on school environment and during the break (Vaillancourt, Brittain, Bennett, Arnocky, McDougall, Hymel, and Cunningham, 2010). In our country, although this has begun sensitivity about the phenomenon's bullying, in the author's knowledge, there is only one study that provides descriptive data on school premises with the highest frequency of bullying behaviors. According to reports of the students, in the report study the CDE (2012) result those students feel unsafe in these places namely: a) In the schoolyard their $-11.73 \%$; b) In the school corridor $-6.85 \%$ of the students; c) In the school toilets $22.66 \%$ of students; and d) In the way to school $23.32 \%$ of students.

Bullying behavior among school students in $80 \%$ of cases occur in the presence of other students $\left(O^{\prime}\right.$ Connell, Pepler, and Craig, 1999) what has awakened the interest of researchers to investigate the reactions of spectators to this phenomenon. It is found that the attitudes of people who are on the scene, affecting the continuation of this behavior which means that it can continue and further fed, or terminated depending on how interact present people (Rivers \& Noren, 2010; Rivers, 2012; Salmivalli, Voeten, and Poskiparta, 2011). According to researchers at the act's bullying, bystanders mainly take five roles: 1) Bullies, who takes the initiative to disturb the others; 2) The victim, a person over whom exercised any bullying behavior; 3) Assistants / reinforcers of bullies, person who supports bully and his behavior; 5) Defenders of the victim, individuals who intervene to interrupt violent behavior; and 6) The outsiders, the individual who is indifferent and does not side with any (Olweus 1973, 1978; Salmivalli, Lagerspetz, Bjorkqvist, and Osterman, 1996)

The choice of role (excluding the victim) is dependent on a variety of reasons. Specifically, if a student sees bullying behavior to perform, although have desire to protect the victim, often conditioned by fear of victimized from bully and he or his group and therefore choose not to intervene (Stevens, Bourdeaudhuij, Ilse \& Oost, Paulette 2000). Protective behaviors include the requirement to discontinue bulling, and reporting bullit behavior to teachers, parents or other adults who may be located nearby (Kanetsuna, Smith \& Morita, 2006; Salmivalli, et al., 2011). In some cases, although there are fears of victimization of present person, placed in a difficult position after being friends with the victim, may lose the friendship for reason to stay neutral (Lodge \& Frydenberg, 2005). However, there are other cases, when not to lost friendship with bully and not to feel excluded from the group; the person must present support every footstep. However, it is concluded that peers are better supporters of social perspective in these situations compared to teachers or siblings (Boulton 2005). Even Rigby (2005) in his study confirms that peer interventions are more effective than parents are what reinforce the need to recognize, what is in the attitudes of peers in order to see the possibility to build effective strategies to stop bullying through schools.

There are a number of studies that highlight, gender differences in terms of involvement in bullying behaviors. So by Brown and his colleagues (2007), boys are more involved in physical formats of bullying, while girls in verbal ones. Also found that incidence of bullying by gender perspective is unbalanced, where study results and show that boys are more involved in either role of the bully and in the victim compared to girls (Cerezo, 2009; Cerezo, \& they, 2010; Monks et al., 2003; Perren and Alsaker, 2006). Thus, Cerezo, \& They, (2010), revealed that there were differences statistically significant between boys and girls in terms of experiencing rates of victimization with boys with high percentage of $12.2 \%$, but also in bully behavior with $21.6 \%$ (boys). On the other hand it was found that boys are more intrusive in the ban's 
bullying than girls (Cowie, 2000), where, however, the boys try to hide their sensitivity because it is not perceived as masculine behavior.

Because the literature reviewed above highlight the role that people play in the ban's bullying students, where their interventions were evaluated as more effective than those of teachers and parents and brothers and sisters, said the study aims: 1)To explore students' perceptions about the reasons why some students fall victim's bullying; 2) To explore the location of the high frequency of the phenomenon's bullying; 3) To detect the positions of the spectators of this phenomenon and 4)To detect gender differences' bullying phenomenon.

\section{Methodology}

The study is descriptive quantitative. Based on the literature reviewed, aggressive behaviors have their culmination in early adolescence (Nansel, 2001). In order to realize its goals, data were collected through student reports. For this reason the study sample were pupils of 5-6 th classes of primary school-District of Durres. The sample of this study was randomly selected in six schools of district. During selection of students, the sample was calibrate to maintain the ratio between male / female as one of the goals of the study that was to explore gender differences in involvement of bullying behavior. Specifically sample consists of 230 students aged $11-13$ years of whom $52.6 \%$ were girls $(N=121)$ and $47.4 \%$ boys $(\mathrm{N}=109)$.

For purposes of the study was adapted from a literature, a survey of "The Bully Survey" (Swearer, 2001) which were selected from four main questions, with their respective options to answer under question. Concretely to measure students' perceptions for the reasons why some students fall victim's bullying was elected; 1) "Why do you think that students in this school bully others?" (Choose all answers that you think are true: a) doggy, to be more popular; $b$ ) to get things as money or items from other students; c) to feel powerful; and to get attention; the student is bullied because of different backgrounds / provincial; d) bullied student is because athletic ability absent; e) bullied student because the body is small, f) bullied student because is overweight; $g$ ) the student is bullied because of a different sexual orientation; h) the student is bullied because has wardrobe not like others; i) bullied student has a disability and k) other (please specify).

To measure places with greater bullying frequency's in schools environment became three questions: 2) Do you have excited any of students (in every way physical, verbal, indirect, internet) in the last month? '(Choose the answer that you really think: a) Yes b) No); 3) Do excited you (in any way physical, verbal, indirect, internet) in the last month? '(Choose the answer that you think really, a) Yes b) No) 4) "Where you been, where you are physically harassed, verbally or indirectly in the past?" (Choose all answers that you think that are true: a) in a class (while the teacher was outside the classroom); b) in a class (while the teacher was present in the classroom) ; c) in the bath; d) in corridors ; e) in the school yard ; f) in the stairs, in the activities; g) On the way to or from school (walking, etc.) ; and h) other (please specify).

To measure students' reactions present at the scene when the bullying behavior occurs was used this question: 5 ) "How do you usually react when you see a student being bullied at school?" (Choose all answers that you think that are true: a) I've never seen anyone being bullied in our school ; b) I join the harassers to harass and me this student ; c) I see but not join with student harassing ; d) I try to stop bullying by talking to those involved, ; e) I tell to a teacher or another adult, ; f) Do nothing ; g) I would like to help her, but I do not know what to do, and ; h) Other (please specify).

To respect the ethics of research, before applying measuring instrument was done meetings with parents, explaining to parents the purpose and importance of the study and then were asked their permission to involve their children in this study. Before students to fulfill measuring instrument, became a clarification for what it's bullying and when a behavior defined as such and what are some of the main forms' bullying. Data collection was conducted during the period December-January 2013-14. For processing of data was used statistical package for social science (SPSS, v. 19).

\section{Results}

\subsection{Students' perceptions about the reasons why some students fall victim's bullying}

By answering the question "Why do you think that students in this school bully others?" where students would choose all the answers that they think that are true, these findings result: $4.8 \%$ or 11 students answered "doggy "; $5.2 \%$ or 12 students answered" to be more popular, " ; 7.4\% or 17 students answered" to get things such as money or items to other students "; $8.7 \%$ or 20 students answered" feel strong "; $7.4 \%$ or 20 students answered" to get attention "; $17.8 \%$ or 41 students answered" the student is bullied because of different backgrounds / provincial ",; $10.4 \%$ or 24 students answered" because bullied student have lacks athletic ability "' $7.4 \%$ or 17 students answered" because bullied pupil is 
small by the body "; $9.1 \%$ or 21 students answered" because bullied student is overweight "; $2 \%$ or 5 students answered" because bullied student is of a different sexual orientation "; $16.5 \%$ or 38 students answered" because bullied student has a wardrobe not like others "; and $3 \%$ or 7 students answered" because bullied student has a disability "

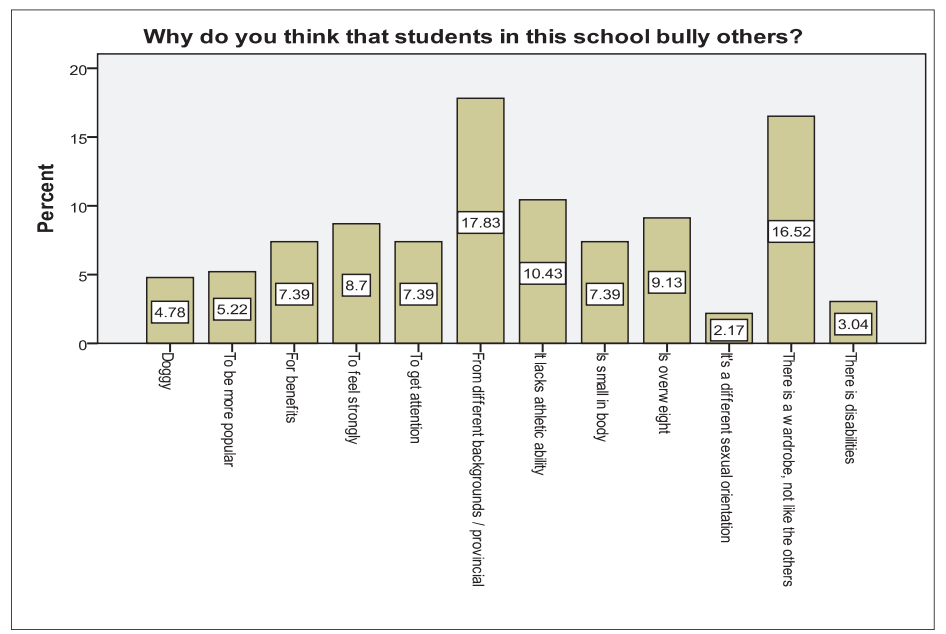

Graph 1. Percentages of students' perceptions of the reasons Why students exert over other's bullying

\subsection{Location with high frequency phenomenon's bullying}

The study revealed that $33 \%$ or 76 students have shown (with their response "not have harassed me in last 2 months" that are not affected by the phenomenon's bullying. Thus, there are a significant percentage of students, which is about $77 \%$ proving that they are affected by the phenomenon's bullying. This is the percentage of students plead that it is involved in bullying at various environments. When asked where they were when suffered bullying at various forms, students' responses show that's bullying occurs in different physical environments. Specifically: $15.7 \%$ or 36 students answered "in a classroom (the class while the teacher was out)"; $7.8 \%$ or 18 students answered "in a class (while the teacher was present in the classroom)"; $5.7 \%$ or 13 students are answered "in the bathroom"; $11.3 \%$ or 26 students answered " in the corridors"; $6.5 \%$ or 15 students answered "in the school yard"; $12.6 \%$ or 29 students answered " in the stairs"; $6.3 \%$ or 14 students are answered "at extracurricular activities" and; $1.2 \%$ or 3 students answered "on the way to or from school (walking, etc.)"

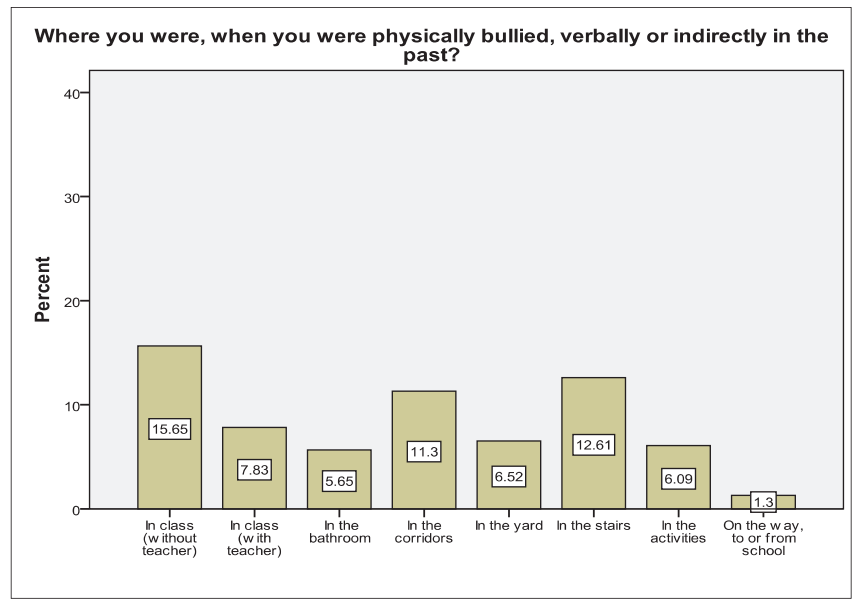

Graph 2. Percentage of incidence of bulling by location 


\subsection{The Attitudes of present students}

To measure present students' attitudes in cases where the bullying behavior occurs was used question: "How do you usually react when you see a student being bullied at school?" Percentages and frequencies of students' reactions' bullying in this study are as follows below. Firstly, the results showed not any pupils that have not seen the in his / her school, pupils on whom exercised bullying. This was show and the percentage of zero to answer, "I've never seen anyone being bullied in our school". Results show the phenomenon reactions are the most varied: $7 \%$ or 16 students responded to "I join the harassers, harassing me this student"; $27 \%$ or 62 students answered "I see but not join that student harassing"; $22.6 \%$ or 52 students answered "I try to stop bullying by talking to those involved; "24.3\% or 56 students answered" I tell a teacher or another adult "; $12.2 \%$ or 28 students answered" when I have friend / companion I try to stop bullying, but when I did not have friend / companion ,I not involved at all "; $2.2 \%$ or 5 students answered" do nothing"; and $4.8 \%$ or 11 students answered" I would help her, but I do not know what to do. "

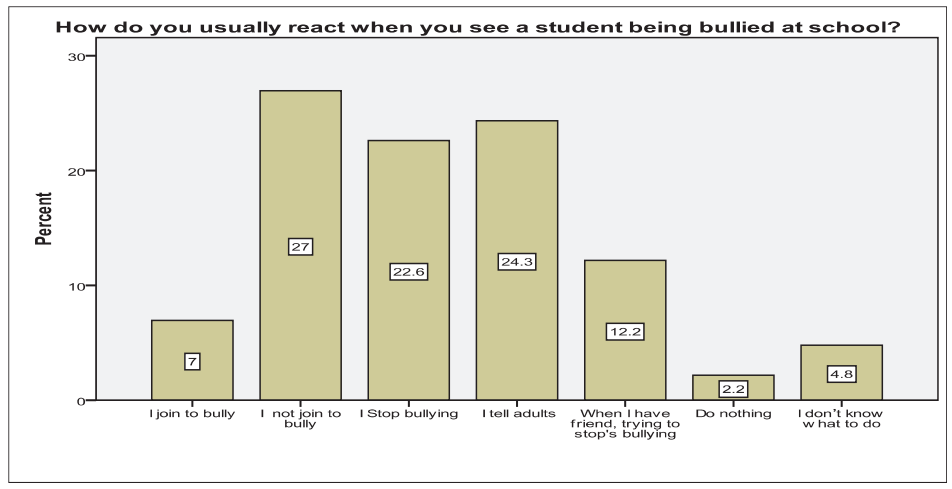

Graph 3. Percentages of students' reactions again bullying

\subsection{Gender differences for bullying phenomenon.}

To understand gender differences regarding the inclusion in bullying behavior as for terms of victimization as well as being the aggressor, analyzes were conducted comparing the averages by t-test, which resulted not statistically significant. To verify once more gender differences were conducted correlation analyzes. From this analysis it is observed that although there is a weak positive relationship between gender and victimhood's bullying, but the aggressor (bull) relationship is not statistically significant, which means that no matter if you are a girl or son to be a victim of the bull's or bullying. On the other hand noted that there is weak link but no statistically significant between victimization and being the aggressor (bull).

Table 4. Relationship between gender and victimhood bullying

\begin{tabular}{lccc}
\hline & 1 & 2 & 3 \\
\hline 1. Gender & 1 & & \\
2. Victim of bullying & .261 & 1 & \\
3. Bull & .212 & $.271^{*}$ & 1 \\
\hline
\end{tabular}

note: ${ }^{*} p<0,05 .{ }^{* *} p<0,01$.

\section{Discussion}

One of the goals of this study was the discovery of student perceptions about the reasons why some students fall victim's bullying. Findings indicated that the bullying attacks were made mainly to students who are different from others. The highest percentage reported by the student on the reasons of falling victim related the: origin of families ( $17.8 \%$ of students), followed by a descending sequence of; changes in the way we dress (16.5\% of students); lack of athletic skills $(10.4 \%$ students), or Being overweight ( $9.1 \%$ of students). It is noted that the last three reasons related to students' 
appearance, which is the important enough for students of this age. The findings are consistent with several studies conducted recently. In these studies explained that bullying victims under peers are those who are deviant in some directions and not conform to the norms of the group. Mostly they are different in dress, appearance, behavior or way of communication. (Frisén et al, 2007, 2008; Hamarus and Kaikkonen, 2008; Thornberg, 2010; Thornberg and Knutsen, 2011).

The fact that in this study the main reason, was declared parentage, connected with the hypothesis of social inadequacy of Wright and his colleagues (1986). Recent years have occurred in Albania, massive displacement of the population of northeast regions of the country and southern regions, which have disadvantaged in terms of economic development. County of Tirana and Durres regions are areas in which there are more migrate people. Changes in habits and lifestyle that makes students that are coming from these areas, are targeted by bulls, which according to this study perform bullying behavior for doggy $12.2 \%$ and for strong feeling in $8.7 \%$ of cases. In these conditions, even those who do not conduct themselves bullying behavior, not offer society to those who are under center of attack, because they fear that they might lose their friends (Hamarus and Kaikkonen, 2008). For this reason, teachers should pay particular attention to these students, not only raped but also not to isolated due to cultural changes that come as a result of family origin. Furthermore, the findings related with the theory of stigma (Goffman, 1963) and labeling (Becker, 1963). According to Becker $(1963, p$ 9) "social group create deviance by making the rules infraction constitutes whose deviance, and by applying those rules to particular people and labeling them as outsiders". While according to Goffman (1963), students with different behavior from group, constitutes group of individuals that violent rules norms and standards, thus explaining the reason for labeling and thus legitimizing's bullying.

The study revealed that's bullying occurs in different environments school, but given the percentages listed from highest percentage to lowest, was found that children suffer more bullying in the class during the breaks when the teacher is not in the class $(15.6 \%)$, to the stairs of the school during entrance and exit $(12.6 \%)$ and in the corridors (11.3\%). All these facilities are reportedly dangerous students because they are not supervised. The findings are different from those of the study conducted in 2012 by CDE, when results those hazardous environments for bullying in school are toilets, the way to school and yard. While Vaillancourt researcher and his colleagues in 2010, a study conducted in Canada with 11,152 students from grades 4-12, they found that among primary school students and older, there were significant differences for environments that constituted a threat to their security. Hazardous environments by students at elementary school are yard, and break time. However, in both cases for elementary students as well as those with adult, places where there were more acts exactly bullying places are lacked supervision of school staff (Vaillancourt, Brittain, Bennett, Arnocky, McDougall, Hymel, \& Cunningham, 2010).

In this study schoolyard, was estimated dangerous and proved as $6.5 \%$, but it should be noted that three of the six schools where the study was conducted, there were almost no yard for reason that they being surrounded on four sides by buildings, while in teaching was done in one of the schools with three shifts for the reasons of reconstruction due to another school, and for this reason students are excluded from long breaks and not stay in the school yard. Furthermore, data was collected during the months from December to January, and because of cold weather and wet, long breaks placed in classrooms without teacher presence, what is explain in the high percentage of bullying behavior in classes during break. In addition, during winter children in most cases accompanied by parents at school for the reasons of the rain at last month, because they avoid bullying on roads school - house and vice versa.

As witnesses and present in a high percentage of bullying behavior, peer attitude is very important for stopping the bullying behavior. Specifically this study found that almost 1 in 3 students tend to report whether adults are present when these behaviors occur, 1 in 4 students results that see event without becoming party with bully but not interfere, and 1 in 5 pupil's trying to stop bullying. In addition, $12.2 \%$ intervene to stop bullying act only if they have a friendship with the victim, and $7 \%$ of students tend to join with every footstep with bully. The findings of the studies in the world are different from this study in terms of four key roles that take attendees. The methodology used in these studies, to measure what is different does not allow comparison of findings.

In contrast to the studies, mentioned in the review of literature (Brown, 2007; Cerezo, \& Ato, 2010; Cerezo, 2009; Cowie, 2000; Monks et al., 2003; Perren and Alsaker, 2006), in this study was not found there are gender differences regarding bullying behavior (victim / bull). One explanation for this finding may be the high level of violence in our schools that makes girls as aggressive as boys and that forces them, to lose the sensitivity that characterizes the need to defend himself. However based on the findings of this study, we will suggest some further studies to understand the precise reasons for this change. In addition, we suggest study of individual characteristics and contextual factors that support or disrupt the possibility for bullying behavior as victims and bulls but also those who are present and praising the role of them as crucial in terminating behavior. Prior to generalize the findings of this study should be taken into account its limitations. Firstly, the small number of samples makes the findings to be valuable mainly for schools in which the study 
was conducted. The study is mainly descriptive and gives some facts on which need deepen further in future studies.

However, based on the findings of this study, we recommend increasing of staff supervision during breaks in classes, supervision of school entrances and exits together with corridors. Moreover, teachers must be attentive to identify between students, students who appear different from others in many aspects, because it constitutes a growing possibility of being the victim's bullying. In order to reduce the school's bullying must be built anti-bulling strategy. Students themselves are an extremely important factor to stop these behaviors. An efficient way of prohibition, is also reporting of bullying to the teachers. However, we think it should work with parents that they to build appropriate attitudes to their children to reject violence and to denounce it. In addition, teachers should work with students to understand that is bullying behavior is not right and therefore punishable and to increase courage to intervene to stop it. For teachers in terms of increasing violence in schools, it is necessity participation in programs not only for work for depth's recognition of theoretical bullying, have findings of studies that show that teachers do not know enough phenomenon (Kashahu and Karaj 2014 in print), but also in programs for building effective strategies to create friendly schools, free from any kind of violence.

\section{References}

Becker HS. 1963. Outsiders: Studies in the Sociology of Deviance. The Free Press of Glencoe: New York.

Besag VE. (2006). Understanding Girls' Friendships, Fights and Feuds: A Practical Approach to Girls' Bullying. Open University Press: New York.

Brown, L. M., Chesney-Lind, M., \& Stein, N. (2007). Toward a gendered theory of teen violence and victimization. Violence Against Women, 13, 1249-1273.

Burns S, Maycock B, Cross D, Brown G. (2008). The power of peers: why some students bully others to conform. Qualitative Health Research 18: 1704-1716.

$\mathrm{CDE}$, (2012) Fletë informuese mbi bulling në shkollat shkollat 9-vjeçare

Cerezo, F. (2009). Bullying. Análisis de la situación en las aulas españolas. International Journal of Psychology and Psychological Therapy, 9(3), 383-394.

Cerezo, F., \& Ato, M. (2010). Social status, gender, classroom climate and bullying among adolescent students. anales de psicología,26(1),137-144

Cowie, H. (2000). Bystanding or standing by: Gender issues in coping with bullying in English schools. Aggressive Behavior, 26,85 - 97.

Frisén A, Holmqvist K, Oscarsson D. (2008). 13-year-olds' perception of bullying: definitions, reasons for victimisation and experience of adults' response. Educational Studies 34: 105-117.

Frisén A, Jonsson A-K, Persson C. (2007). Adolescents' perception of bullying: who is the victim? Who is the bully? What can be done to stop bullying? Adolescence 42: 749-761.

Goffman E. 1963. Stigma. Simon \& Schuster: New York.

Greene, M.B. (2006). 'Bullying in schools: a plea for a measure of human rights'. Journal of Social Issues, $62: 63-79$.

Guerra, N. G., \& Leidy, M. (2008). Lessons learned: Recent advances in the prevention and treatment of childhood aggression. In R. Kail (Ed.), Advances in child development and behavior (Vol. 36, pp. 287-330). Boston: Elsevier.

Hamarus P, Kaikkonen P. (2008). School bullying as a creator of pupil pressure. Educational Research 50: 333-345.

Hamarus P, Kaikkonen P. (2008). School bullying as a creator of pupil pressure. Educational Research 50: 333-345.

Jones, S. E., Haslam, S. A., York, L., \& Ryan, M. K. (2008). Rotten apple or rotten barrel? Social identity and children's responses to bullying. British Journal of Developmental Psychology, 26, 117-132.

Kashahu-Xhelilaj L. dhe Karaj (2014) Perceptimet dhe Qëndrimet e Msuesve dhe Drejtuesve të Shkollave 9-Vjecare mbi Fenomenin e Bullizmit. BJES in press

Lam DOB, Liu AWH. (2007). The path through bullying - a process model from the inside story of bullies in Hong Kong secondary schools. Child and Adolescent School Work Journal 24: 53-75.

Monks , C., Smith, P.K. and Swettenham, J. (2003). 'Aggressors, victims and defenders in preschool: peer, self and teacher reports '. Merrill-Palmer Quarterly , 49 : $453-69$.

Nansel, T. R., Overpeck, M., Pilla, R. S., Ruan, W. J., Simons-Morton, B., \& Scheidt, P. (2001). Bullying behaviors among US youth. Journal of the American Medical Association, 16, 2094-2100.

Nelson , D.A. , Hart , C.A. , Yang , C. , Olsen , J.A. and Jin , S. (2006). 'Aversive parenting in China: associations with child physical and relational aggression'. Child Development , $77: 554-72$.

O'Connell, P., Pepler, D., \& Craig, W. (1999). Peer involvement in bullying: Insights and challenges for intervention. Journal of Adolescence, 22, 437-452. doi: 2048/10.1006/jado.1999.0238

Olweus , D. (1999). 'Sweden'. In P.K. Smith , Y. Morita , J. Junger-Tas , D. Olweus, R.Catalano and P. Slee (eds.), The Nature of School Bullying: A Cross-national Perspective (pp. 7-27). London and New York: Routledge .

Olweus, D. (1973) 'Personality and aggression' in COLE, J. K. and JENSEN, D. D. (eds), Nebraska Symposium on Motivation 1972, Lincoln, University of Nebraska Press.

Olweus, D. (1978) Aggression in the schools: bullies and whipping boys, Washington DC, Hemisphere Press (Wiley).

Olweus, D. (1993). Bullying at School: What We Know and What We Can Do. Oxford: Blackwell. 
Olweus, D. (1999). Sweden. In P. K. Smith, Y. Morita, J. Junger-Tas, D. Olweus, R. Catalano, \& P. Slee (Eds.), The nature of school bullying: A cross-national perspective (pp. 7-27). Florence, KY: Routledge.

Ortega, R. and Monks, C.P. (2005). 'Agresividad injustificada entre preescolares: un estudio preliminary [Unjustified aggression between preschoolers: a preliminary study]'. Psicothema , $17: 453-58$.

Ostrov , J.M. (2008). ' Forms of aggression and peer victimisation during early childhood: a short-term longitudinal study'. Journal of Abnormal Child Psychology , $36: 311-22$.

Perren , S. and Alsaker, F.D. (2006). ' Social behavior and peer relationships of victims, bully-victims, and bullies in kindergarten '. Journal of Child Psychology and Psychiatry , $47: 45-57$.

Perren, S. and Alsaker , F.D. ( 2006 ). ' Social behavior and peer relationships of victims, bully-victims, and bullies in kindergarten '. Journal of Child Psychology and Psychiatry , $47: 45-57$.

Rigby, K. (2002). New perspectives on bullying. London: Jessica Kingsley.

Rivers, I. (2012). Morbidity among bystanders of bullying behavior at school: concepts, concerns, and clinical/ research issues. International Journal of Adolescent Medicine and Health, 24(1), 11-16. doi: 10.1515/ ijamh.2012.003

Rivers, I., Noret, N. (2010). Participant roles in bullying behavior and their association with thoughts of ending one' s life. Crisis Journal of Crisis Intervention and Suicide Prevention, 31, 143 - 148. doi: 10.1027/0227- 5910/a000020

Ross , D.M. (2002). Childhood Bullying and Teasing. What School Personnel, Other Professionals, and Parents Can Do, 2nd edn. Alexandria, VA : American Counseling Association .

Russell , A. , Hart , C.H. , Robinson, C.C. and Olsen , S.F. ( 2003 ). ' Children's sociable and aggressive behavior with peers: a comparison of the U.S. and Australia and contribution of temperament and parenting styles '. International Journal of Behavioral Development , $27: 74-86$.

Salmivalli, C., Lagerspetz, K., Björkqvist, K., Österman, K., \& Kaukiainen, A. (1996). Bullying as a group process Participant roles and their relations to social status within the group. Aggressive

Shahim, S. (2008). 'Sex differences in relational aggression in preschool children in Iran'. Psychological Reports , 102 : 235 -38.

Shin, Y. and Kim, H.Y. ( 2008 ). ' Peer victimization in Korean preschool children: the effects of child characteristics, parenting behaviours and teacher-child relationships '. School Psychology International , 29 : $590-605$.

Solberg, M. E., \& Olweus, D. (2003). Prevalence estimation of school bullying with the Olweus bully/victim questionnaire. Aggressive Behavior, 29, 239-268.

Stevens, V., Bourdeaudhuij, I., \& Oost, P. (2000). Bullying in Flemish schools: An evaluation of anti-bullying intervention in primary and secondary schools. British Journal of Educational Psychology, 70(2), 195-210.

Swearer, S. M. (2001). The Bully Survey. Unpublished manuscript. The University of Nebraska - Lincoln

Thornberg R, Knutsen S. (2011). Teenagers' explanations of bullying. Child \& Youth Care Forum.

Thornberg R. (2010). Schoolchildren's social representations on bullying causes. Psychology in the Schools 47: 311-327.

Thornberg R. 2010. Schoolchildren's social representations on bullying causes. Psychology in the Schools 47: 311-327.

Vaillancourt, T., Brittain, H., Bennett, L., Arnocky, S., McDougall, P., Hymel, S., \& Cunningham, L. (2010). Places to avoid: Populationbased study of student reports of unsafe and high bullying areas at school. Canadian Journal of School Psychology, 25(1), 40-54.

Wright JC, Giammarino M, Parad HW. (1986). Social status in small groups: individual - group similarity and the social "misfit". Journal of Personality and Social Psychology 50: 523-536. 